\title{
How Forces Fold the Cerebral Cortex
}

\author{
(C) Christopher D. Kroenke ${ }^{1}$ and $\odot$ Philip V. Bayly ${ }^{2}$ \\ ${ }^{1}$ Oregon National Primate Research Center Division of Neuroscience, Advanced Imaging Research Center, and Department of Behavioral Neuroscience, \\ Oregon Health \& Science University, Portland, Oregon 97239, and ²Department of Mechanical Engineering and Materials Science, Washington University, \\ St. Louis, Missouri 63130
}

Improved understanding of the factors that govern folding of the cerebral cortex is desirable for many reasons. The existence of consistent patterns in folding within and between species suggests a fundamental role in brain function. Abnormal folding patterns found in individuals affected by a diverse array of neurodevelopmental disorders underline the clinical relevance of understanding the folding process. Recent experimental and computational efforts to elucidate the biomechanical forces involved in cerebral cortical folding have converged on a consistent approach. Brain growth is modeled with two components: an expanding outer zone, destined to become the cerebral cortex, is mechanically coupled to an inner zone, destined to become white matter, that grows at a slower rate, perhaps in response to stress induced by expansion from the outer layer. This framework is consistent with experimentally observed internal forces in developing brains, and with observations of the folding process in physical models. In addition, computational simulations based on this foundation can produce folding patterns that recapitulate the characteristics of folding patterns found in gyroencephalic brains. This perspective establishes the importance of mechanical forces in our current understanding of how brains fold, and identifies realistic ranges for specific parameters in biophysical models of developing brain tissue. However, further refinement of this approach is needed. An understanding of mechanical forces that arise during brain development and their cellular-level origins is necessary to interpret the consequences of abnormal brain folding and its role in functional deficits as well as neurodevelopmental disease.

Key words: biomechanics; development; fetal brain; gyrus; morphology

\section{What is to be gained from understanding how the cerebral cortex folds}

Understanding the relationships between structure and function in biology is critical to the development of desirable interventions. For example, on the molecular scale, impaired enzymatic catalysis can be explained in terms of an aberrant protein folding pattern. On the scale of human epidemiology, descriptions of disease rely on structural models of the affected populations. A structure-function conundrum that has challenged neuroanatomists for more than a century is how (or if) the folding pattern of the cerebral cortex of gyrencephalic mammals reflects brain function (Welker, 1990).

The association of aberrant cerebral cortical folding patterns in humans with a diverse array of neurodevelopmental disorders demonstrates a clear clinical need to more completely understand the underlying mechanics of folding. Congenital brain abnormalities, such as lissencephaly, polymicrogyria, and pachygyria, are associated with severe mental deficits (Richman et al., 1974,

\footnotetext{
Received July 20, 2017; revised Nov. 15, 2017; accepted Nov. 20, 2017.

This work was supported by National Institutes of Health Grants R01AA021981, 0D011092, R01NS070918, and R21EB005834, and National Science Foundation Grant DMS-0540701.

The authors declare no competing financial interests.

Correspondence should be addressed to Dr. Christopher D. Kroenke, Oregon Health \& Science University, 3181 SW Sam Jackson Park Road, MailCode L452, Portland, OR 97239. E-mail: kroenkec@ohsu.edu.

DOI:10.1523/JNEUROSCI.1105-17.2017

Copyright $\odot 2018$ the authors $\quad 0270-6474 / 18 / 380767-09 \$ 15.00 / 0$
}

1975; Barkovich et al., 2005; Barkovich and Raybaud, 2012; Manzini and Walsh, 2015); these gross pathologies of folding represent extreme examples of linkages between structural characteristics and brain function. More subtle folding differences from age-matched, typically developing control groups have been described for individuals with autism spectrum disorder (Nordahl et al., 2007; Blanken et al., 2015; Dierker et al., 2015; Ecker et al., 2015), Williams syndrome (Van Essen et al., 2006), and schizophrenia (White et al., 2003; Csernansky et al., 2008). The presence of folding abnormalities in these disorders of poorly understood etiology highlights the importance of a more complete understanding of the folding process. In addition, developmental impairments arising from environmental insults, such as premature birth (Zhang et al., 2015), intrauterine growth restriction (Dubois et al., 2008), and fetal alcohol exposure (Hendrickson et al., 2017), also result in abnormal folding patterns associated with functional deficits. Understanding the biomechanics that govern cerebral cortical folding during development may illuminate the developmental processes responsible for an abnormally folded cerebral cortex at maturity, and provide insight into the mechanism of specific disorders.

Consistent relationships between the location of primary sulci and cytoarchitectural as well as functional boundaries (Welker, 1990; Fischl et al., 2008) suggest that folding is involved in the process of regional differentiation of the cortex. Consistent folding patterns are found within a given gyroencephalic species, and 
between closely related species (Zilles et al., 2013). Furthermore, evidence that the gyral and sulcal pattern observed in human brains is heritable (Bartley et al., 1997; Rogers et al., 2010) suggests that molecular and cellular processes influence the shape of the folded brain at maturity.

This review focuses on recent developments in the approach to characterizing the mechanical forces that arise from and give rise to cerebral cortical folding. The three main objectives in this review are as follows: (1) to provide an overview of current state of the art in biomechanical studies of cortical folding, (2) to describe the progress made to date in our understanding of the involvement of mechanical forces in this process, and (3) to identify shortcomings of currently used approaches, as these represent opportunities for significant advances in this field. Recently described mechanical models have the ability to recapitulate many developmental and structural characteristics of cerebral cortical gyri and sulci found across species. As described below, this approach has illuminated the interaction between mechanical forces and brain tissue material properties to produce folds. Fundamental physics and mathematics provide important constraints for the development of hypotheses related to how cellular processes influence folding. However, although several recent advances have been made in the biophysical characterization of cerebral cortical folding, a current shortcoming is the need to further refine mechanical models in terms of recently identified cellular developmental processes demonstrated to be influential in cortical folding.
G85, 23\% folded

a

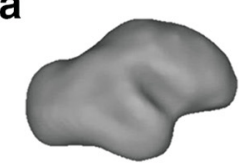

G110, 47\% folded

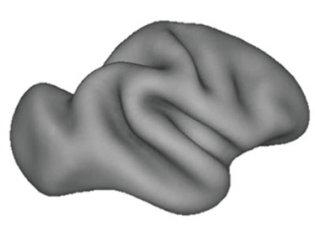

G135, $87 \%$ folded

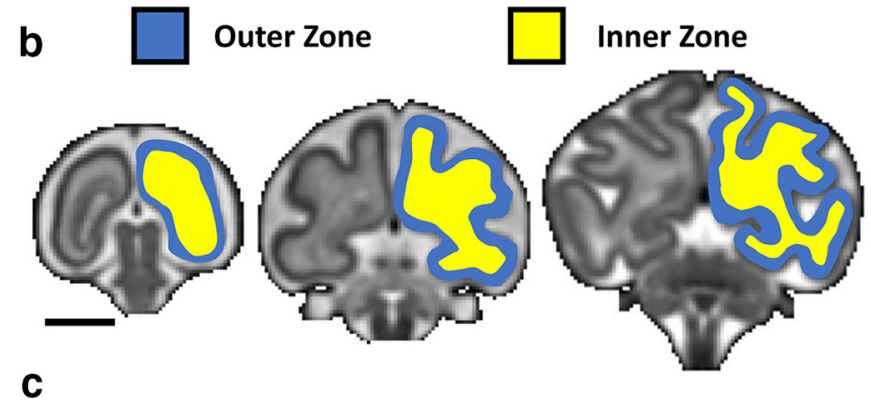

C
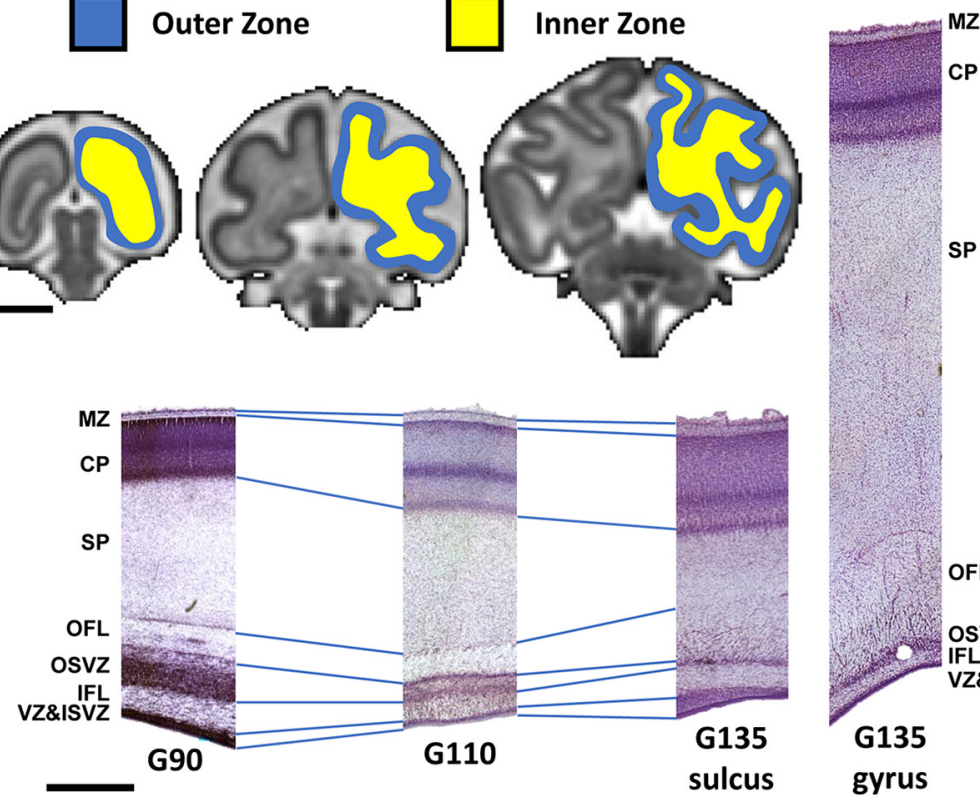

SP

OFL

OSVZ IFL VZ\&ISVZ

Figure 1. Cerebral cortical folding, as approximated in physical models, and in relation to developmental changes in tissue zones identified by light microscopy. $\boldsymbol{a}$, Lateral views of models of the rhesus macaque cerebral cortex obtained from fetal MRI measurements at gestation ages G85, G110, and G135. Gestation term is $168 \mathrm{~d}$ for rhesus macaques. The mean normalized curvature, a measure of folding, increases from $23 \%$ to $87 \%$ of the adult value from G85 to $\mathrm{G} 135$ (Wang et al., 2017). $\boldsymbol{b}$, Average coronal T2-weighted fetal MRI from $17 \mathrm{G} 85$ brains, 8 G110 brains, and $16 \mathrm{G} 135$ brains (manuscript in preparation). $S$ cale bar, $1 \mathrm{~cm}$. Illustrations of the outer (blue) and inner (yellow) zones for one hemisphere are overlaid on the hemisphere portrayed on the right at each age. c, Nissl-stained images spanning from the ventricular zone to the pial surface in the inferior temporal lobe of a G90, G110, and G135 brain. For the G135 brain, cerebral tissue is shown for a sulcal and gyral region. Lamina are labeled according to Smart et al. (2002). Notable changes in thickness for several layers, including the cortical plate, occur over this period. MZ, Marginal zone; CP, cortical plate; SP, subplate; OFL, outer fibrous layer; OSVZ, outer subventricular zone; IFL, inner fibrous layer; ISVZ, inner subventricular zone; VZ, ventricular zone. Scale bar, $1 \mathrm{~mm}$.

\section{A common framework for simulating cerebral cortical folding}

Computational and experimental approaches for studying the biomechanical forces that govern folding have converged in recent years on a common framework (Fig. 1). In gyroencephalic mammals, the process of folding begins approximately at the conclusion of pyramidal cell neurogenesis. At this time, the immature cortex, termed the cortical plate, is a cell-dense zone near the pial surface (Bystron et al., 2008). The cell-sparse subplate zone borders the cortical plate on the ventricular side, and spans the space separating the cortical plate and fibrous tissue termed the intermediate zone (Kostović et al., 2002; Bystron et al., 2008; Huang et al., 2009), the outer fibrous layer (Smart et al., 2002), or other (Altman and Bayer, 2002; Bayer and Altman, 2005; Barkovich and Raybaud, 2012) as reviewed by Wang et al. (2015, their Table 1). In computational modeling of cerebral cortical folding, the brain before the appearance of sulci and gyri is represented as a structure consisting of two zones (Fig. 1b) (Richman et al., 1975; Bayly et al., 2013; Budday et al., 2014a; Tallinen et al., 2014; Zhang et al., 2016; Ben Amar and Bordner, 2017). The outer zone represents the cortical plate, and the inner zone represents the tissue between the cortical plate and ventricular surface.
Within this simplified two-zone framework, one question that has drawn attention concerns whether the governing forces arise from tissue within the outer layer or inner layer. Two contrasting theories propose different answers to this question. According to the cortical "buckling due to differential expansion" theory (Richman et al., 1975), compressive forces arise in the outer layer as a consequence of its tangential expansion relative to the inner zone, and these forces lead to buckling of the cortex. Alternately, the "axon tension" theory (Van Essen, 1997) posited that tension derived from axons in the inner zone acts to fold the cortex by pulling gyral walls toward one another.

Two sets of experimental findings provide support for the view that forces within the outer zone are dominant in the folding process. The first line of evidence counters the white matter tension hypothesis. Direct measurements of tension mediated by axons were made by introducing incisions in the developing white matter of slices of immature ferret brains (Xu et al., 2010). In such studies, when tension exists perpendicular to the incision direction, the cut will open, allowing the tension to relax. Tissue deformations in these brain slices following incision indicated that (1) axons do exhibit tension, but (2) the directions of forces exerted by axons will not pull the walls of gyri together. These 
observations are inconsistent with a prominent role for axon tension in forming gyri (Bayly et al., 2014). The second line of evidence affirms that forces derived from simple tangential expansion of the outer layer can cause intricate folding of the surface. In elegant polymer preparations, a gel structure can be induced to undergo surface area expansion by exposing the surface to a catalyst that penetrates a controlled distance into the gel (Dervaux et al., 2011; Tallinen et al., 2014, 2016). This experimental system has been used to demonstrate that, when the physical size and material properties of the gel are made similar to developing brain, a fast-expanding outer shell bounded to a slower expanding inner shell forms folds that resemble the sizes and shapes of human cerebral cortical sulci and gyri (Tallinen et al., 2016).

It should be noted that, whereas a dominant role for tangential outer-zone forces is now commonly assumed in biomechanical simulations, several other potential scenarios have been suggested that remain to be quantitatively assessed. Among these, a longrecognized possibility (for review, see Welker, 1990) is that gyri arise from localized radial growth within the inner zone that occurs at a greater rate than in sulcal regions. As examples, (Smart and McSherry, 1986a, b) note, in the developing ferret brain, that "during the folding of the surface of the hemisphere, the floors of the sulci remain relatively fixed both in relation to the deep surface of the cortex and to each other and ... a gyrus is produced by the expansion of the intersulcal tissue." Kostović and Rakic (1990) suggest a potential role of the subplate zone by noting that "regional differences in subplate thickness occur in register with the emergence of sulci and gyri and the peak in the size of the subplate zone coincides with the establishment of gyral pattern." Elegant morphometric analyses of detailed, in utero whole-brain fetal MRI studies of the developing human brain have also characterized growth in subcortical as well as cortical tissue (Rajagopalan et al., 2011). However, the difficulty encountered with inferring mechanistic information from observational studies is that a region can undergo an increase in its volume both as a result of its growth (in which case it exerts force on the surrounding tissue) or as a result of the growth of neighboring tissue (and the deformation is a consequence of forces imposed on it). Indeed, localized radial growth is difficult to reconcile with biomechanical force measurements in the developing ferret brain. Specifically, if gyri are to form from the inner zone "pushing" the outer zone outward, compressive radial force would be anticipated in the center of developing gyri. In direct opposition to this prediction, tensile forces in this region of the inner zone are actually observed (Xu et al., 2010). Another factor that has warranted consideration is the potential influence of the surrounding meninges and skull on cortical folding. However, a majority of experimental evidence does not favor this hypothesis (Welker, 1990). Thus, although current biomechanical approaches may be well motivated by the available experimental biomechanical data, there are several proposed mechanisms of folding that remain to be rigorously evaluated.

\section{Computational simulations of cerebral cortical folding}

Mathematical models of the two-zone framework enable precise and quantitative investigation of the hypothesis that tangential growth-related forces play a role in shaping the cerebral cortex. Brain growth is modeled using an approach developed by Rodriguez et al. (1994) to compactly describe changes in preferred tissue size or shape, with some modification as detailed below. In these simulations, parameters specified as input include the initial geometry of the system, the material properties of the two zones, and characteristics of growth within the tissue components. It should be noted that each of these parameters can be explicitly set in folding simulations and thus adjusted to replicate folding patterns observed in brains. As will be discussed in subsequent sections, an important remaining need is to develop understanding of the cellular processes responsible for the phenomena reflected in these computational parameters.

\section{Initial geometry}

Finite element simulations of cerebral cortical folding have been performed on 2D and 3D systems. In 2D simulations and approximate equations, the effects of various physical parameters on folding size and shape have been substantiated. The thickness of the outer zone as well as its rate of tangential expansion relative to the inner zone both influence the wavelength of the folds formed (Bayly et al., 2013; Budday et al., 2014a). Initial curvature of the surface also plays an important role in subsequent folding. Standard idealized initial geometries for 2D simulations are rectangular domains or curved surfaces, such as sections of concentric circles (representing the boundaries of the inner and outer zones), or ellipses. In $3 \mathrm{D}$ simulations, the initial geometry can also be an idealized structure, such as a sphere or ellipsoid (Bayly et al., 2013), or it can be defined to more closely resemble biological conditions. For example, Tallinen et al. (2016) used in utero MRI data to define the initial surface mesh of the outer zone to simulate folding of the human cerebral cortex.

\section{Material properties}

Developing brain tissue has been modeled as a growing, soft, nonlinear, elastic ("hyperelastic") material (Bayly et al., 2014). In a finite element simulation, a given area (2D) or volume (3D) element may undergo growth, governed by specific equations describing material behavior and expansion. If growth is constrained, or nonuniform, it will induce mechanical stresses in affected area or volume elements and on their neighboring elements, causing the tissue to deform. This, in turn, can induce additional stress on neighboring area or volume elements. It is quite likely that these stresses can affect the processes that cause growth itself, closing a very consequential feedback loop. In the context of this tissue model, critical parameters that determine how the tissue responds to mechanical stress are the tissue inner and outer zone stiffnesses, or the ratio between the two stiffnesses. Stiffness (more precisely: elastic modulus) quantifies the constitutive relationship that links forces (stress) in tissue to its deformation (strain). Early theoretical analysis of a two-layered, static, elastic model of the brain (Richman et al., 1975) concluded that compression in the outer layer, due to cortical growth, would cause buckling and the formation of folds resembling gyri and sulci. In this model, the wavelengths of folds are realistic only if the outer zone is considerably stiffer than the inner zone. Several measurements of brain tissue stiffness have since been reported (e.g., for review, see Chatelin et al., 2010); and although there is some discrepancy between studies on whether gray matter (the outer zone) or white matter (the ultimate identity of the inner zone) is stiffer (Weickenmeier et al., 2016), it is generally held that these two tissue subtypes are not as distinctly different as postulated by Richman et al. (1975). In more recent dynamic simulations of growth using the formalism of Rodriguez et al. (1994), performed since the studies of Richman et al. (1975), conditions have been found in which realistic folding patterns occur in the absence of significant differences in stiffness between tissue subtypes, as described below. 
One shortcoming in our current knowledge of material properties for the inner zone is the potential effects of changes with development. Weickenmeier et al. (2016) have noted regional variation in white matter stiffness throughout the brain, and comparisons with histological measurements have identified myelin content as an important factor. Considering that, over the period in which cortical folding occurs, the inner zone corresponds to the developmentally transient tissue zones, such as the subplate (Kostović and Rakic, 1990; Hoerder-Suabedissen and Molnár, 2015), rather than (myelinated) white matter, stiffness measurements performed on immature brains would be of value. Developmental studies have revealed differences in brain tissue stiffness between the newborn and mature porcine and rat brain (Thibault and Margulies, 1998; Prange and Margulies, 2002; Gefen et al., 2003). Even these, however, have focused on white matter subsequent to myelin development. Stiffness measurements of the subplate remain to be reported.

Characteristics of growth

A common assumption is that growth in the outer layer is purely tangential, such that, if unconstrained, the surface area of the cortex would increase with time but the cortical thickness would remain constant (Bayly et al., 2014). This tangential growth is termed "morphogenic" by Kuhl and coworkers (Budday et al., 2014a, b), as it is the primary force-generating process that causes the outer zone to buckle. In reality, thickness as well as surface area are known to increase over the period of time in which folding occurs; but as recognized by Tallinen et al. (2016), the approximately twofold increase in thickness is very small compared with the 30-fold increase in surface area in human brain development. We note that constrained tangential cortical growth could lead to increased thickness by the "Poisson effect"; external compression of most materials in one direction leads to passive expansion in the perpendicular directions. As described below, the structural characteristics of folds are predicted by simulations to be very sensitive to the thickness of the outer zone; therefore, the potential influence of changes in thickness with development remains to be further characterized. Surface area expansion of the cerebral cortex over the period of cortical folding has been documented in longitudinal MRI studies of some species: ferret (Knutsen et al., 2013), rhesus macaque (Wang et al., 2017), baboon (Kochunov et al., 2010), and human (Dubois et al., 2008; Clouchoux et al., 2012; Habas et al., 2012). And in these cases, surface area increases as an approximately linear function of age throughout the formation of primary gyri and sulci. Interestingly, linear surface area expansion continues beyond the period in which folding occurs (Wang et al., 2017) (Fig. 2), indicating that surface area expansion and folding are distinct attributes of cortical development.

An important advance in the conceptualization of brain growth was the recognition that, although tangential growth of the outer zone may be the primary generator of forces that drive folding, the formation of folds also induces stress on the inner zone, which in turn can cause stress-dependent growth (Bayly et al., 2013). Mechanical stress-induced growth of nerve cell processes is a well-characterized phenomenon (Chada et al., 1997; Franze et al., 2013). Stress-induced inner-zone growth has been made explicit by treating the inner zone as a "Maxwell fluid" in recent simulations (Bayly et al., 2013). A Maxwell fluid acts like an elastic solid when resisting rapidly applied forces but flows like a viscous liquid in response to gradual changes in force. Through the addition of this stress-induced growth term in the inner zone, dynamic simulations were observed to generate buckling-induced folds using realistic inner and outer zone stiffness parameters, and produced stress fields qualitatively consistent with mechanical measurements (Bayly et al., 2013). Tallinen et al. (2014), also using a dynamic model of folding, similarly found that reasonable wavelengths could be obtained, with realistic stiffnesses in each layer, by controlling relative growth rates in the outer and inner layer.

\section{Evaluating simulation results}

The extent and structure of folds

A first question in the evaluation of simulation results is whether a biologically plausible folding pattern was formed. A second, perhaps more important question, is whether perturbations in the simulation lead to changes in model behavior (output) that match corresponding responses to perturbation in the biological system. 
A useful answer to either question requires quantitative characterization of folded shapes in $2 \mathrm{D}$ and $3 \mathrm{D}$. The most widely used folding metric for the brain is the gyrification index: the ratio of the surface area of the folded cortex to the area of its convex hull (Zilles et al., 1988; Sallet et al., 2003; Hardan et al., 2004). In 3D simulations, the ratio of the exposed to total surface area has been reported (Tallinen et al., 2014). Mean curvature, sulcal depth, and other measures of shape have also been used to quantify the degree of folding (Van Essen, 2005; Wright et al., 2014; Shimony et al., 2016). Among the sets of parameters for quantifying folding, nondimensional ones have the advantage that they can be used to compare brains of different sizes. Nondimensional mean curvature and nondimensional sulcal depth, which are normalized by characteristic radius of the surface $L_{c}=\sqrt{\text { Area/4 } \pi}$, were proposed and used by Knutsen et al. (2013).

In simulations, the folding wavelength can be used (Bayly et al., 2013; Shimony et al., 2016) as a metric to distinguish folding scale (polymicrogyria vs normal vs pachygyria). Mathematical models show consistently that greater mean thickness of the outer zone increases folding wavelength (Goriely and Ben Amar, 2005; Dervaux et al., 2011; Bayly et al., 2013; Budday et al., 2014a; Tallinen et al., 2014). Some models show that wavelength also increases when growth rate of the outer zone is slower relative to the growth of the inner zone (Bayly et al., 2013; Tallinen et al., 2016). These predictions are consistent with general observations of thin cortex in polymicrogyria and thicker cortex in pachygyria, and with the effects of increased (Chenn and Walsh, 2002) or impaired neurogenesis (Johnston et al., 1982; Poluch and Juliano, 2015) on folding in animal brains. Although systematic comparison is lacking between the effects of corresponding perturbations in simulation and experiment, existing evidence clearly establishes that the outer-zone growth-dependent buckling mechanism, as conceptualized in dynamic simulations of growth, is consistent with the biological process of gyrogenesis.

\section{Specifying the locations of folds: the effects of initial geometry and heterogeneous growth}

Each gyroencephalic species exhibits consistencies in the folding pattern among individuals, and similarities are also found between closely related species (Zilles et al., 2013). For the viewpoint that expansion-based buckling drives cortical folding, the source of regularity in folding patterns is a challenging question. Two potential sources of reproducible patterns have been explored with computational simulations. The first is the specification of initial geometry for the cortical plate. The second possibility is that a regionally specific growth process occurs, which confers consistency in folding.

Simulations (Bayly et al., 2013; Tallinen et al., 2016) have confirmed that small variations in the shape of the brain at the start of rapid tangential expansion are amplified by the folding process. The most elaborate investigation of the influence of initial geometry on ultimate folding pattern in simulations was performed by Tallinen et al. (2016), in which initial shapes were derived from in utero MRI data collected from human fetuses. Complementary experiments were performed using simulations and the layered expanding gel system, with a 3D printed former being used to specify the initial geometry for the expanding gel. Both the simulations and expanding gel system produced gyral and sulcal structures comparable in size with each other and with those found in human brain. Further, simulations and expanding gel experiments that were initiated using the same initial geometry produced consistent folds. However, differences were observed between the simulations and experimentally observed folding patterns, and both of these differed from the folding pattern observed in humans. Nevertheless, this work demonstrates that initial geometry can influence the ultimate locations of folds, but additional information is needed to produce the folding pattern observed in vivo.

In addition to the initial geometry of the brain at the onset of folding, multiple researchers have suggested that regional heterogeneity in growth could act as a source of reproducible folding. One characteristic of species with gyroencephalic brains is the presence of enlarged subplate and subventricular zones relative to those observed in lissencephalic species (Kostović and Rakic, 1990; Smart et al., 2002; Kriegstein et al., 2006). Recognition of the importance of the subventricular zone in neurogenesis (Kriegstein et al., 2006; Lui et al., 2011), combined with the observation of regional patterns in subventricular zone thickness that correlate with subsequent locations of sulci and gyri (Smart et al., 2002; Kriegstein et al., 2006; Reillo et al., 2011), has led to the suggestion that subventricular zone neurogenesis determines the locations of cortical folds. Reillo et al. (2011) have characterized the nonuniform distribution of specific populations of radial glial progenitor cells in the developing ferret brain, which reside in the subventricular zone. In addition to their role as neural progenitors (Lui et al., 2011), these cells support the tangential dispersion of neurons originating from a given ventricular or subventricular location over a region of the cortex. Notably, interference with the number of these radial progenitor cells through experimental manipulation, such as the elimination of input from the retina (Reillo et al., 2011), has been shown to reduce the extent of folding of the cerebral cortex at maturity.

Although multiple lines of experimental evidence support that regional patterns in neurogenesis can determine folding patterns of the mature brain, it is notable that most cell division is complete by the time that folding takes place. From the biomechanical perspective, subsequently occurring biological processes must mediate the forces that are simultaneous with fold formation. As originally noted by Richman et al. (1975), the timing of morphological development of axonal and dendritic arbors is more closely coupled to the formation of folds than is neurogenesis. As further acknowledged by Ronan and Fletcher (2015), axons could influence cortical folding, not through introducing direct axonal tension, but by "controlling regional maturation" (Dehay et al., 1991; O'Leary et al., 2007) rather than "exerting mechanical forces" (Van Essen, 1997). Thus, one possibility is that the locations of gyri and sulci are determined by regional patterns of neurogenesis by populating the cortical plate with regionally varying density of cells, and subsequent differentiation of these cells generates regionally varying forces that produce folds.

In addition to the issue of the biological source of regional folding patterns, consensus remains to be reached on the relative magnitude of the effects of local versus global surface expansion in the formation of folds. Ronan and coworkers (Ronan et al., 2014; Ronan and Fletcher, 2015) offer a view representing one extreme: that tangential surface area expansion is highly regional and intrinsically linked to cytoarchitectural development and the formation of folds. A contrasting viewpoint is that only small, localized, and transient perturbations to a development process can be sufficient to establish a consistent folding pattern in the presence of rapid tangential expansion. Bayly et al. (2013) showed in simulations of folding that minor deformations can produce regularly arranged folds. MRI studies of cortical development have documented regional patterns in surface area expansion (Rajagopalan et al., 2011; Knutsen et al., 2013; Wang et 
al., 2017), and these have shown that the regional pattern does not sharply vary with cortical location, suggesting a more subtle relationship between folding and differential cortical expansion. Improved understanding of the biological process(es) that potentially contribute to reproducible regional variation, as well as their magnitude relative to overall surface area expansion, will require future experimental work to inform and refine how simulations are executed and interpreted.

\section{Future directions: characterizing the cellular bases of forces that control cortical folding}

A large body of recent experimental and computational work has advanced the postulate that tangential, growth-dependent instability is the primary factor generating forces that fold the cerebral cortex. Nevertheless, much work remains before it is possible to infer biological mechanisms of a neurodevelopmental disorder based on an altered pattern of folding in the mature brain. To move toward more complete understanding, (1) refinements to the modeling strategy and implementation are likely needed, and (2) the cell-biological processes represented by simulation input parameters must be identified.

\section{Refinements to the two-zone framework}

Comparison of the two-zone model with diagrams of laminar organization in brains of gyroencephalic species (Fig. $1 b$ vs Fig. 1c) illustrates that the two-zone model is highly simplified. The outer zone corresponds to the marginal zone and the cortical plate, and laminar heterogeneity is notable within the cell-dense region destined to become the cerebral cortex. The inner zone contains an even more diverse array of tissue zones, including the subplate, the outer fibrous layer of the intermediate zone, the outer subventricular zone, the inner fibrous layer, inner subventricular zone, and ventricular zone (Smart et al., 2002; Bystron et al., 2008). Material properties have not been measured for these specific subregions of the inner zone. Potential effects of variability in stiffness between them has not been simulated. Moreover, stiffness values for the inner and outer zones should be determined over the entire range of developmental stages in which folding occurs. Last, the effects of changes in outer zone (cortical) thickness, both global and regional, over the course of the folding process have yet to be theoretically investigated.

\section{Hypothesized cell-biological processes responsible for intracortical} forces that cause buckling

If tangential growth of the cortex is the source of the forces that produce folds, then the biological processes that underlie tangential growth are implicated in the neurodevelopmental disorders associated with abnormal folding. Recently, Striedter et al. (2015) proposed the "radial intercalation" hypothesis, which attributes folding to forces generated by newly migrated neuronal cell bodies intercalating between existing neurons within the densely populated cortical plate. This hypothesis is attractive because it puts forth an explanation for tangential growth, as well as force within the cortex, that is consistent with buckling. However, quantitative estimates of the forces and growth rates produced by intercalation have not yet been made. Such biomechanical information is ultimately necessary to rigorously assess this hypothesis.

One problem with the radial intercalation hypothesis concerns the timing of neuron integration into the cortical plate relative to cortical folding. Figure 2 provides a timeline of brain development over the period in which folding takes place. As documented previously (Knutsen et al., 2013; Wang et al., 2017), folding largely occurs over the interval from postnatal day $(\mathrm{P}) 10$ to P30 in ferrets, gestation days (G)90 to G135 in rhesus ma- caques, and in humans from the 25th week of gestation to a postnatal age of 4 months. Immediately before folding, surface area expansion is approximately threefold slower than it is during the period in which folding occurs (Knutsen et al., 2013; Wang et al., 2017). The slow phase of surface area expansion is associated with neurogenesis and migration of neurons to the cortical plate. Thus, as acknowledged by Striedter et al. (2015), neuronal intercalation is almost complete before folding begins. The transition from slow to fast surface area expansion is associated with the onset of folding and is coincident with the initiation of neuronal morphological expansion of dendritic and axonal arbors (Richman et al., 1975). The strong associations between neuronal morphological development and folding favors, as an alternative to the radial intercalation hypothesis, that cellular morphological maturation produces the intracortical forces that drive cortical folding.

To examine this possibility, an experimental method that can quantify morphological complexity of developing cells in the cerebral cortex is needed. Morphological complexity of large populations of cells can be difficult to quantify using traditional light microscopy because the standard method involves manually tracing neuronal processes. However, MRI measurement of cerebral cortical water diffusion anisotropy provides a quantitative aggregate measure of cellular complexity in the developing cerebral cortex (Kroenke et al., 2009), and can be performed on animal and human subjects in vivo, and even in utero (Jiang et al., 2007; Studholme, 2011). In early stages of cortical development, apical dendrites are radially oriented, and have simple morphology that generally lacks collaterals, and water diffusion is highly directionally dependent, or "anisotropic." This is because membranes of radially oriented structures impede water diffusion parallel to the cortical surface tangent plane, but in the direction perpendicular to the surface, water diffusion is relatively unimpeded. As development proceeds, axonal, and apical and basal dendritic arbors grow in directions that provide pathways for water to diffuse parallel to the local tangent plane, and diffusion anisotropy decreases. In a diffusion MRI study of the cortex of prematurely born human infants, McKinstry et al. (2002) suggested that anisotropy decreases with cortical maturation as a consequence of the growth of axonal and dendritic collaterals. In support of this, the distributions of orientations in neural (and glial) processes have been measured with $3 \mathrm{D}$ confocal microscopy techniques, and have demonstrated that the addition cellular elements oriented at varying directions relative to the cortical surface accompanies maturation of the cortex (Jespersen et al., 2012; Wang et al., 2017). Direct comparisons between diffusion MRI and histological measurements of cellular complexity have demonstrated strong correlations between anisotropy in water diffusion and anisotropy in the orientation distribution of cellular processes within an MRI voxel (Bock et al., 2010; Jespersen et al., 2012; Wang et al., 2017).

Figure 2 summarizes changes in cortical surface area, folding, and diffusion anisotropy as a function of age for ferrets, rhesus macaques, and humans, three species in which longitudinal imaging data are available. Ages for the three species are registered to each other through calculation of the interspecies developmental "event time" defined by Workman et al. (2013). As indicated by the red curve, cortical folding attains a mature pattern at an event time of $\sim 0.7$. Similarly, water diffusion anisotropy decreases to the value observed at maturity over the same developmental period. Moreover, it has also been demonstrated that regional patterns of diffusion anisotropy follow regional patterns of folding in longitudinal studies of newborn ferrets (Knutsen et al., 2013) 
and rhesus macaque fetuses (Wang et al., 2017). This neuroimaging data demonstrate a close connection between morphological development of cells within the cerebral cortex and the appearance of folds. An important next step for evaluating the role of morphological development of elements of the neuropil will be to relate these cellular changes to forces and growth rates at both cell and tissue levels.

In conclusion, the folding of the cerebral cortex is simultaneously a complex physical phenomenon, an important clinical issue, and a fundamental question in neurobiology, basic to our understanding of brain development and evolution. In recent years, the mechanical factors that underlie cortical folding have been studied by mathematical modeling and simulation, advanced imaging, and elegant experimental studies. Thus, cortical folding research exemplifies a new paradigm in which interactions between modelers, imagers, and experimental scientists enable advances within disparate scientific disciplines to contribute new insight into a complex problem. This approach has provided evidence for the prominent role of tangential cortical expansion, and the possible effects of initial (prefolding) geometry and regional growth patterns. This review highlights the importance of further study to understand the underlying relationships of macroscopic, mechanical parameters, such as force and growth, to cell-biological processes, such as neuronal proliferation, migration, differentiation, and morphological development. As a result, a phase of rapid expansion in knowledge is anticipated, which promises deeper understanding of brain folding in normal development and disease.

\section{Response from Dual Perspectives Companion} Author-Victor Borrell

Christopher D. Kroenke and Philip V. Bayly provide a thorough review of research, models, and hypotheses on the biomechanical aspects of cerebral cortex folding. They acknowledge the value of our work and that from others demonstrating that cortical folding can be manipulated by altering radial glia cell proliferation, neurogenesis, and neuronal migration (Nonaka-Kinoshita et al., 2013; Stahl et al., 2013; Del Toro et al., 2017). Importantly, however, Kroenke and Bayly highlight that the actual buckling of the cortex does not overlap in time with these early events of cortical development, but it begins only once these are largely over. Based on this, they argue that the biomechanical forces driving cortical folding do not derive from these early events, but to others occurring later, namely, neuron differentiation (dendrite and axon arborization) and neuropile expansion.

Kroenke and Bayly review experimental and modeling data from their laboratory and others to make a compelling case that the biomechanics of cortical folding is based on different expansion speeds between an outer cortical layer (faster) and an inner core (slower), which also have different deformation properties, as proposed first by Richman et al. (1975). These outer and inner layers correspond to the cortical plate (where neurons differentiate) and the subjacent transition and germinal layers, respectively. Together, they propose here that the elaboration of dendritic arbors within the cortical plate drives its faster expansion compared with the deeper layers; thus, it is the source of laterally pushing forces that drive cortical plate buckling late in development. Although this is a very appealing idea, it is not well supported by detailed analyses of neuronal differentiation in the developing ferret cortex (Borrell and Callaway, 2002; Callaway and Borrell, 2011). These show that dendritic arborization of neurons in layers $2 / 3$ and 4 is still very poor at P14, a stage of exponential increase in folding, whereas it increases exponentially between P21 and P30, when folding reaches its plateau (Kroenke and Bayly, their Fig. 2). Moreover, our experimentally induced reduction of cortical fold size in ferret by early enucleation is not related to compacting of cortical neurons in the tangential axis, as should occur according to the model of Kroenke and Bayly, but to neuronal compacting in the radial axis (Reillo et al., 2011). Rather, this is in agreement with the notion that tangential dispersion of radially migrating neurons mediated by basal radial glia cells (referred to as "radial intercalation" by Striedter et al., 2015), although occurring at an early time in development, is central in setting up the appropriate conditions for the eventual folding.

An unresolved question of the model by Kroenke and Bayly is how the folding patterns are defined. Cortical folds form in a highly stereotypical and hierarchical fashion during embryogenesis, with primary folds forming the earliest, then secondary folds elaborating on top of those, etc. These patterns do not form randomly but are very well conserved. Transcriptional analyses in developing ferret, before cortical folding, demonstrate temporal and spatial patterns of gene expression consistent with protomaps of primary cortex folding (de Juan Romero et al., 2015; Fernandez et al., 2016; Martinez-Martinez et al., 2016). Understanding the role of these transcriptional protomaps in sculpting cortical development should illuminate on the cell-biological processes involved in folding, maybe including patterned variations in the physical and mechanical properties of cortical tissue. Although early events, such as neurogenesis and radial migration, clearly do not exert biomechanical forces to fold the developing cortex, they do seem to set up the regional variations in cell density that will later on translate into regionally varying forces to produce folds. In summary, it takes two to fold the cortex: cells and forces.

\footnotetext{
References

Borrell V, Callaway EM (2002) Reorganization of exuberant axonal arbors contributes to the development of laminar specificity in ferret visual cortex. J Neurosci 22:6682-6695. Medline Callaway EM, Borrell V (2011) Developmental sculpting of dendritic morphology of layer 4 neurons in visual cortex: influence of retinal input. J Neurosci 31:7456-7470. CrossRef Medline de Juan Romero C, Bruder C, Tomasello U, Sanz-Anquela JM, Borrell V (2015) Discrete domains of gene expression in germinal layers distinguish the development of gyrencephaly. EMBO J 34:1859-1874. CrossRef Medline

Del Toro D, Ruff T, Cederfjäll E, Villalba A, Seyit-Bremer G, Borrell V, Klein R (2017) Regulation of cerebral cortex folding by controlling neuronal migration via FLRT adhesion molecules. Cell 169:621-635.e16. CrossRef Medline

Fernández V, Llinares-Benadero C, Borrell V (2016) Cerebral cortex expansion and folding: what have we learned? EMBO J 35:1021-1044. CrossRef Medline
} 
Martínez-Martínez MÁ, De Juan Romero C, Fernández V, Cárdenas A, Götz M, Borrell V (2016) A restricted period for formation of outer subventricular zone defined by Cdh1 and Trnp1 levels. Nat Commun 7:11812. CrossRef Medline

Nonaka-Kinoshita M, Reillo I, Artegiani B, Martínez-Martínez MA, Nelson M, Borrell V, Calegari F (2013) Regulation of cerebral cortex size and folding by expansion of basal progenitors. EMBO J 32:1817-1828. CrossRef Medline

Reillo I, de Juan Romero C, García-Cabezas MÁ, Borrell V (2011) A role for intermediate radial glia in the tangential expansion of the mammalian cerebral cortex. Cereb Cortex 21:1674-1694. CrossRef Medline

Richman DP, Stewart RM, Caviness VS Jr (1974) Cerebral microgyria in a 27-week fetus: an architectonic and topographic analysis. J Neuropathol Exp Neurol 33:374-384. CrossRef Medline

Stahl R, Walcher T, De Juan Romero C, Pilz GA, Cappello S, Irmler M, Sanz-Aquela JM, Beckers J, Blum R, Borrell V, Götz M (2013) Trnp1 regulates expansion and folding of the mammalian cerebral cortex by control of radial glial fate. Cell 153:535-549. CrossRef Medline

Striedter GF, Srinivasan S, Monuki ES (2015) Cortical folding: when, where, how, and why? Annu Rev Neurosci 38:291-307. CrossRef Medline

\section{References}

Altman J, Bayer SA (2002) Regional differences in the stratified transitional field and the honeycomb matrix of the developing human cerebral cortex. J Neurocytol 31:613-632. CrossRef Medline

Barkovich AJ, Raybaud C (2012) Pediatric neuroimaging. Philadelphia, PA: Lippincott Williams and Wilkins.

Barkovich AJ, Kuzniecky RI, Jackson GD, Guerrini R, Dobyns WB (2005) A developmental and genetic classification for malformations of cortical development. Neurology 65:1873-1887. CrossRef Medline

Barkovich AJ, Guerrini R, Kuzniecky RI, Jackson GD, Dobyns WB (2012) A developmental and genetic classification for malformations of cortical development: update 2012. Brain 135:1348-1369. CrossRef Medline

Bartley AJ, Jones DW, Weinberger DR (1997) Genetic variability of human brain size and cortical gyral patterns. Brain 120:257-269. CrossRef Medline

Bayer SA, Altman J (2005) The human brain during the second trimester. Boca Raton, FL: CRC.

Bayly PV, Okamoto RJ, Xu G, Shi Y, Taber LA (2013) A cortical folding model incorporating stress-dependent growth explains gyral wavelengths and stress patterns in the developing brain. Phys Biol 10:016005. CrossRef Medline

Bayly PV, Taber LA, Kroenke CD (2014) Mechanical forces in cerebral cortical folding: a review of measurements and models. J Mech Behav Biomed Mater 29:568-581. CrossRef Medline

Ben Amar M, Bordner A (2017) Mimicking cortex convolutions through the wrinkling of growing soft bilayers. J Elasticity 1-26.

Blanken LM, Mous SE, Ghassabian A, Muetzel RL, Schoemaker NK, El Marroun $\mathrm{H}$, van der Lugt A, Jaddoe VW, Hofman A, Verhulst FC, Tiemeier H, White T (2015) Cortical morphology in 6- to 10-year old children with autistic traits: a population-based neuroimaging study. Am J Psychiatry 172:479-486. CrossRef Medline

Bock AS, Olavarria JF, Leigland LA, Taber EN, Jespersen SN, Kroenke CD (2010) Diffusion tensor imaging detects early cerebral cortex abnormalities in neuronal architecture induced by bilateral neonatal enucleation: an experimental model in the ferret. Front Syst Neurosci 4:149. CrossRef Medline

Budday S, Steinmann P, Kuhl E (2014a) The role of mechanics during brain development. J Mech Phys Solids 72:75-92. CrossRef Medline

Budday S, Raybaud C, Kuhl E (2014b) A mechanical model predicts morphological abnormalities in the developing human brain. Sci Rep 4:5644. CrossRef Medline

Bystron I, Blakemore C, Rakic P (2008) Development of the human cerebral cortex: Boulder Committee revisited. Nat Rev Neurosci 9:110-122. CrossRef Medline

Chada S, Lamoureux P, Buxbaum RE, Heidemann SR (1997) Cytomechanics of neurite outgrowth from chick brain neurons. J Cell Sci 110:11791186. Medline
Chatelin S, Constantinesco A, Willinger R (2010) Fifty years of brain tissue mechanical testing: from in vitro to in vivo investigations. Biorheology 47:255-276. CrossRef Medline

Chenn A, Walsh CA (2002) Regulation of cerebral cortical size by control of cell cycle exit in neural precursors. Science 297:365-369. CrossRef Medline

Clouchoux C, Kudelski D, Gholipour A, Warfield SK, Viseur S, BouyssiKobar M, Mari JL, Evans AC, du Plessis AJ, Limperopoulos C (2012) Quantitative in vivo MRI measurement of cortical development in the fetus. Brain Struct Funct 217:127-139. CrossRef Medline

Csernansky JG, Gillespie SK, Dierker DL, Anticevic A, Wang L, Barch DM, Van Essen DC (2008) Symmetric abnormalities in sulcal patterning in schizophrenia. Neuroimage 43:440-446. CrossRef Medline

Dehay C, Horsburgh G, Berland M, Killackey H, Kennedy H (1991) The effects of bilateral enucleation in the primate fetus on the parcellation of visual cortex. Brain Res Dev Brain Res 62:137-141. CrossRef Medline

Dervaux J, Couder Y, Guedeau-Boudeville MA, Ben Amar M (2011) Shape transition in artificial tumors: from smooth buckles to singular creases. Phys Rev Lett 107:018103. CrossRef Medline

Dierker DL, Feczko E, Pruett JR Jr, Petersen SE, Schlaggar BL, Constantino JN, Harwell JW, Coalson TS, Van Essen DC (2015) Analysis of cortical shape in children with simplex autism. Cereb Cortex 25:1042-1051. CrossRef Medline

Dubois J, Benders M, Borradori-Tolsa C, Cachia A, Lazeyras F, Ha-Vinh Leuchter R, Sizonenko SV, Warfield SK, Mangin JF, Hüppi PS (2008) Primary cortical folding in the human newborn: an early marker of later functional development. Brain 131:2028-2041. CrossRef Medline

Ecker C, Bookheimer SY, Murphy DG (2015) Neuroimaging in autism spectrum disorder: brain structure and function across the lifespan. Lancet Neurol 14:1121-1134. CrossRef Medline

Fischl B, Rajendran N, Busa E, Augustinack J, Hinds O, Yeo BT, Mohlberg H, Amunts K, Zilles K (2008) Cortical folding patterns and predicting cytoarchitecture. Cereb Cortex 18:1973-1980. CrossRef Medline

Franze K, Janmey PA, Guck J (2013) Mechanics in neuronal development and repair. Annu Rev Biomed Eng 15:227-251. CrossRef Medline

Gefen A, Gefen N, Zhu Q, Raghupathi R, Margulies SS (2003) Age-dependent changes in material properties of the brain and braincase of the rat. J Neurotrauma 20:1163-1177. CrossRef Medline

Goriely A, Ben Amar M (2005) Differential growth and instability in elastic shells. Phys Rev Lett 94:198103. CrossRef Medline

Habas PA, Scott JA, Roosta A, Rajagopalan V, Kim K, Rousseau F, Barkovich AJ, Glenn OA, Studholme C (2012) Early folding patterns and asymmetries of the normal human brain detected from in utero MRI. Cereb Cortex 22:13-25. CrossRef Medline

Hardan AY, Jou RJ, Keshavan MS, Varma R, Minshew NJ (2004) Increased frontal cortical folding in autism: a preliminary MRI study. Psychiatry Res 131:263-268. CrossRef Medline

Hendrickson TJ, Mueller BA, Sowell ER, Mattson SN, Coles CD, Kable JA, Jones KL, Boys CJ, Lim KO, Riley EP, Wozniak JR (2017) Cortical gyrification is abnormal in children with prenatal alcohol exposure. Neuroimage Clin 15:391-400. CrossRef Medline

Hoerder-Suabedissen A, Molnár Z (2015) Development, evolution and pathology of neocortical subplate neurons. Nat Rev Neurosci 16:133-146. CrossRef Medline

Huang H, Xue R, Zhang J, Ren T, Richards LJ, Yarowsky P, Miller MI, Mori S (2009) Anatomical characterization of human fetal brain development with diffusion tensor magnetic resonance imaging. J Neurosci 29:42634273. CrossRef Medline

Jespersen SN, Leigland LA, Cornea A, Kroenke CD (2012) Determination of axonal and dendritic orientation distributions within the developing cerebral cortex by diffusion tensor imaging. IEEE Trans Med Imaging 31: 16-32. CrossRef Medline

Jiang S, Xue H, Counsell S, Anjari M, Allsop J, Rutherford M, Rueckert D, Hajnal JV (2007) In-utero three dimension high resolution fetal brain diffusion tensor imaging. Med Image Comput Comput Assist Interv 10: 18-26. Medline

Johnston MV, Haddad R, Carman-Young A, Coyle JT (1982) Neurotransmitter chemistry of lissencephalic cortex induced in ferrets by fetal treatment with methylazoxymethanol acetate. Brain Res 256:285-291. Medline

Knutsen AK, Kroenke CD, Chang YV, Taber LA, Bayly PV (2013) Spatial and temporal variations of cortical growth during gyrogenesis in the developing ferret brain. Cereb Cortex 23:488-498. CrossRef Medline

Kochunov P, Castro C, Davis D, Dudley D, Brewer J, Zhang Y, Kroenke CD, 
Purdy D, Fox PT, Simerly C, Schatten G (2010) Mapping primary gyrogenesis during fetal development in primate brains: high-resolution in utero structural MRI of fetal brain development in pregnant baboons. Front Neurosci 4:20. CrossRef Medline

Kostović I, Rakic P (1990) Developmental history of the transient subplate zone in the visual and somatosensory cortex of the macaque monkey and human brain. J Comp Neurol 297:441-470. CrossRef Medline

Kostović I, Judas M, Rados M, Hrabac P (2002) Laminar organization of the human fetal cerebrum revealed by histochemical markers and magnetic resonance imaging. Cereb Cortex 12:536-544. CrossRef Medline

Kriegstein A, Noctor S, Martínez-Cerdeño V (2006) Patterns of neural stem and progenitor cell division may underlie evolutionary cortical expansion. Nat Rev Neurosci 7:883-890. CrossRef Medline

Kroenke CD, Taber EN, Leigland LA, Knutsen AK, Bayly PV (2009) Regional patterns of cerebral cortical differentiation determined by diffusion tensor MRI. Cereb Cortex 19:2916-2929. CrossRef Medline

Lui JH, Hansen DV, Kriegstein AR (2011) Development and evolution of the human neocortex. Cell 146:18-36. CrossRef Medline

Manzini MC, Walsh CA (2015) The genetics of brain malformations. In: The genetics of neurodevelopmental disorders (Mitchell KJ, ed), pp 181214. New York, NY: Wiley.

McKinstry RC, Mathur A, Miller JH, Ozcan A, Snyder AZ, Schefft GL, Almli CR, Shiran SI, Conturo TE, Neil JJ (2002) Radial organization of developing preterm human cerebral cortex revealed by non-invasive water diffusion anisotropy MRI. Cereb Cortex 12:1237-1243. CrossRef Medline

Nordahl CW, Dierker D, Mostafavi I, Schumann CM, Rivera SM, Amaral DG, Van Essen DC (2007) Cortical folding abnormalities in autism revealed by surface-based morphometry. J Neurosci 27:11725-11735. CrossRef Medline

O'Leary DD, Chou SJ, Sahara S (2007) Area patterning of the mammalian cortex. Neuron 56:252-269. CrossRef Medline

Poluch S, Juliano SL (2015) Fine-tuning of neurogenesis is essential for the evolutionary expansion of the cerebral cortex. Cereb Cortex 25:346-364. CrossRef Medline

Prange MT, Margulies SS (2002) Regional, directional, and age-dependent properties of the brain undergoing large deformation. J Biomech Eng 124:244-252. CrossRef Medline

Rajagopalan V, Scott J, Habas PA, Kim K, Corbett-Detig J, Rousseau F, Barkovich AJ, Glenn OA, Studholme C (2011) Local tissue growth patterns underlying normal fetal human brain gyrification quantified in utero. J Neurosci 31:2878-2887. CrossRef Medline

Reillo I, de Juan Romero C, García-Cabezas MÁ, Borrell V (2011) A role for intermediate radial glia in the tangential expansion of the mammalian cerebral cortex. Cereb Cortex 21:1674-1694. CrossRef Medline

Richman DP, Stewart RM, Caviness VS Jr (1974) Cerebral microgyria in a 27-week fetus: an architectonic and topographic analysis. J Neuropathol Exp Neurol 33:374-384. CrossRef Medline

Richman DP, Stewart RM, Hutchinson JW, Caviness VS Jr (1975) Mechanical model of brain convolutional development. Science 189:18-21. CrossRef Medline

Rodriguez EK, Hoger A, McCulloch AD (1994) Stress-dependent finite growth in soft elastic tissues. J Biomech 27:455-467. CrossRef Medline

Rogers J, Kochunov P, Zilles K, Shelledy W, Lancaster J, Thompson P, Duggirala R, Blangero J, Fox PT, Glahn DC (2010) On the genetic architecture of cortical folding and brain volume in primates. Neuroimage 53: 1103-1108. CrossRef Medline

Ronan L, Fletcher PC (2015) From genes to folds: a review of cortical gyrification theory. Brain Struct Funct 220:2475-2483. CrossRef Medline

Ronan L, Voets N, Rua C, Alexander-Bloch A, Hough M, Mackay C, Crow TJ, James A, Giedd JN, Fletcher PC (2014) Differential tangential expansion as a mechanism for cortical gyrification. Cereb Cortex 24:2219-2228. CrossRef Medline

Sallet PC, Elkis H, Alves TM, Oliveira JR, Sassi E, Campi de Castro C, Busatto GF, Gattaz WF (2003) Reduced cortical folding in schizophrenia: an MRI morphometric study. Am J Psychiatry 160:1606-1613. CrossRef Medline

Shimony JS, Smyser CD, Wideman G, Alexopoulos D, Hill J, Harwell J, Dierker D, Van Essen DC, Inder TE, Neil JJ (2016) Comparison of cortical folding measures for evaluation of developing human brain. Neuroimage 125:780-790. CrossRef Medline

Smart IH, McSherry GM (1986a) Gyrus formation in the cerebral cortex in the ferret: I. Description of the external changes. J Anat 146:141-152. Medline
Smart IH, McSherry GM (1986b) Gyrus formation in the cerebral cortex of the ferret: II. Description of the internal histological changes. J Anat 147: 27-43. Medline

Smart IH, Dehay C, Giroud P, Berland M, Kennedy H (2002) Unique morphological features of the proliferative zones and postmitotic compartments of the neural epithelium giving rise to striate and extrastriate cortex in the monkey. Cereb Cortex 12:37-53. CrossRef Medline

Striedter GF, Srinivasan S, Monuki ES (2015) Cortical folding: when, where, how, and why? Annu Rev Neurosci 38:291-307. CrossRef Medline

Studholme C (2011) Mapping fetal brain development in utero using magnetic resonance imaging: the Big Bang of brain mapping. Annu Rev Biomed Eng 13:345-368. CrossRef Medline

Tallinen T, Chung JY, Biggins JS, Mahadevan L (2014) Gyrification from constrained cortical expansion. Proc Natl Acad Sci U S A 111:12667-12672. CrossRef Medline

Tallinen T, Chung JY, Rousseay F, Girard N, Lefevre J, Mahadevan L (2016) On the growth and form of cortical convolutions. Nat Phys 12:588-593. CrossRef

Thibault KL, Margulies SS (1998) Age-dependent material properties of the porcine cerebrum: effect on pediatric inertial head injury criteria. J Biomech 31:1119-1126. CrossRef Medline

Van Essen DC (1997) A tension-based theory of morphogenesis and compact wiring in the central nervous system. Nature 385:313-318. CrossRef Medline

Van Essen DC (2005) A Population-Average, Landmark- and Surface-based (PALS) atlas of human cerebral cortex. Neuroimage 28:635-662. CrossRef Medline

Van Essen DC, Dierker D, Snyder AZ, Raichle ME, Reiss AL, Korenberg J (2006) Symmetry of cortical folding abnormalities in Williams syndrome revealed by surface-based analyses. J Neurosci 26:5470-5483. CrossRef Medline

Wang X, Pettersson DR, Studholme C, Kroenke CD (2015) Characterization of laminar zones in the mid-gestation primate brain with magnetic resonance imaging and histological methods. Front Neuroanat 9:147. CrossRef Medline

Wang X, Studholme C, Grigsby PL, Frias AE, Cuzon Carlson VC, Kroenke CD (2017) Folding, but not surface area expansion, is associated with cellular morphological maturation in the fetal cerebral cortex. J Neurosci 37: 1971-1983. CrossRef Medline

Weickenmeier J, de Rooij R, Budday S, Steinmann P, Ovaert TC, Kuhl E (2016) Brain stiffness increases with myelin content. Acta Biomater 42: 265-272. CrossRef Medline

Welker W (1990) Why does the cortex fissure and fold? A review of determinants of gyri and sulci. In: Cerebral cortex (Jones EG, Peters A, eds), pp 3-136. New York, NY: Plenum.

White T, Andreasen NC, Nopoulos P, Magnotta V (2003) Gyrification abnormalities in childhood- and adolescent-onset schizophrenia. Biol Psychiatry 54:418-426. CrossRef Medline

Workman AD, Charvet CJ, Clancy B, Darlington RB, Finlay BL (2013) Modeling transformations of neurodevelopmental sequences across mammalian species. J Neurosci 33:7368-7383. CrossRef Medline

Wright R, Kyriakopoulou V, Ledig C, Rutherford MA, Hajnal JV, Rueckert D, Aljabar P (2014) Automatic quantification of normal cortical folding patterns from fetal brain MRI. Neuroimage 91:21-32. CrossRef Medline

Xu G, Knutsen AK, Dikranian K, Kroenke CD, Bayly PV, Taber LA (2010) Axons pull on the brain, but tension does not drive cortical folding. J Biomech Eng 132:071013. CrossRef Medline

Zhang T, Razavi MJ, Li X, Chen H, Liu T, Wang X (2016) Mechanism of consistent gyrus formation: an experimental and computational study. Sci Rep 6:37272. CrossRef Medline

Zhang Y, Inder TE, Neil JJ, Dierker DL, Alexopoulos D, Anderson PJ, Van Essen DC (2015) Cortical structural abnormalities in very preterm children at 7 years of age. Neuroimage 109:469-479. CrossRef Medline

Zilles K, Armstrong E, Schleicher A, Kretschmann HJ (1988) The human pattern of gyrification in the cerebral cortex. Anat Embryol (Berl) 179: 173-179. CrossRef Medline

Zilles K, Palomero-Gallagher N, Amunts K (2013) Development of cortical folding during evolution and ontogeny. Trends Neurosci 36:275-284. CrossRef Medline 